\section{AB1320 CLINICAL, IMMUNOLOGICAL AND EXPOSITIONAL FACTORS IN A COLOMBIAN POPULATION WITH SYSTEMIC LUPUS ERYTHEMATOSUS ASSOCIATED WITH LUPUS NEPHRITIS}

J.C. Diaz-Coronado ${ }^{1}$, A. Rojas-Villarraga ${ }^{1}$, D. Hernandez Parra ${ }^{1}$, L. BetancurVasquez $^{2}$, J. Lacouture-Fierro ${ }^{2}$, D. Gonzalez-Hurtado ${ }^{2}$, J. Gonzalez- Arango $^{2}$, L. Uribe- Arango ${ }^{2}$, M.C. Gaviria-Aguilar ${ }^{2}$, P. Perez-Estrada ${ }^{1}$, M.C. Soto-Osorio ${ }^{3}$, R. Pineda-Tamayo ${ }^{1}$, on behalf of grupo de información clinica. ${ }^{1}$ Medical research, artmedica; ${ }^{2}$ Internal medicine; ${ }^{3}$ Medical research, ces university, medellin, Colombia

Background: Systemic lupus erythematosus (SLE) is an autoimmune disease characterised by multiple organ involvement, lupus nephritis $(\mathrm{LN})^{1}$ being one of the most serious manifestations

Objectives: To establish associated factors with lupus nephritis development in patients with SLE

Methods: Cross-sectional study taken from a cohort of 1175 patient with SLE who met criteria for classification for ACR 1997 or, SLICC 2012 between 2007 and 2015. Bivariate analysis of multiple characteristics was performed between patients with presence and absence of $L N$ at through chi squared and $U$ Mann Whitney. Multivariate analysis was performed by logistic regression to adjust for significant associations

Results: The cohort of patients with SLE $90 \%$ was female gender, had an average of 44 years with a duration of the disease of 10.6 years. Joint and haematological involvement was present in more than $80 \%$ of patients. The presence of antibodies against DNA and low complement was found in $53 \%$ and $60 \%$ respectively. The exposure to dyes was $44 \%$ and tobacco $21 \%$.

It was found 455 patients with SLE and LN with an average age of 41 years and a time of evolution of SLE of 11 years. The male gender proportion was higher in those who presented $\mathrm{LN}$ with $11.6 \%$ compared to $7.1 \%$ who did not have $\mathrm{LN}$. The immunological profile of patients with NL was characterised by a higher proportion of positivity for Anti-DNA, anti-SM and low complement. Male gender has a greater association with LN (OR $1.98 \mathrm{Cl} 95 \% 1,20-3,27)$. Having a disease duration greater than 10 years increases the association with LN (OR $1.4895 \% \mathrm{Cl} 1-$ 2,16 ) as well as the presence of anti-DNA (OR 1.34 Cl95\% 1,03-1,75) and antiSM (OR $1.4595 \% \mathrm{Cl}$ 1.04-2.02). Never smoker was a protective factor for LN (OR 0.52 Cl95\% 0.34-0.81).

Abstract AB1320 - Table 1. Factors associated with Lupus nephritis in a cohort of patients with systemic lupus erythematosus, in Colombia from 2007 to 2015

\begin{tabular}{|c|c|c|c|c|}
\hline \multicolumn{5}{|c|}{ Lupus nephritis } \\
\hline & OR & $\mathrm{Cl}(95 \%)$ & $\begin{array}{c}\text { OR } \\
\text { adjust }^{\star}\end{array}$ & $\mathrm{Cl}(95 \%)$ \\
\hline \multicolumn{5}{|l|}{ Gender } \\
\hline Male & 1,27 & $\begin{array}{c}1,04- \\
1,55\end{array}$ & 1,98 & $\begin{array}{l}1,20- \\
3,27\end{array}$ \\
\hline \multicolumn{5}{|c|}{ Time progress SLE ${ }^{a}$} \\
\hline$\geq 10$ years & 1,37 & $\begin{array}{c}1,08- \\
1,74\end{array}$ & 1,48 & $\begin{array}{l}1,01- \\
2,16\end{array}$ \\
\hline \multicolumn{5}{|l|}{ Anti SM } \\
\hline Positive & 1,46 & $\begin{array}{c}1,10- \\
1,95\end{array}$ & 1,45 & $\begin{array}{l}1,04- \\
2,02\end{array}$ \\
\hline \multicolumn{5}{|l|}{ Anti DNA + } \\
\hline Positive & 1,34 & $\begin{array}{c}1,05- \\
1,72\end{array}$ & 1,34 & $\begin{array}{c}1,03- \\
1,75\end{array}$ \\
\hline \multicolumn{5}{|c|}{ Past or current cigarette consumption } \\
\hline Yes & 1,66 & $\begin{array}{l}1,22- \\
2,25\end{array}$ & 1,75 & $\begin{array}{l}1,14- \\
2,69\end{array}$ \\
\hline \multicolumn{5}{|c|}{$\begin{array}{l}\text { No previous or current cigarette } \\
\text { consumption }\end{array}$} \\
\hline Yes & 0,56 & $\begin{array}{c}0,41- \\
0,77\end{array}$ & 0,52 & $\begin{array}{c}0,34- \\
0,81\end{array}$ \\
\hline
\end{tabular}

Conclusions: This study shows a greater association of $L N$ in men. Although there are disparities in the findings worldwide, we believe that other factors typical of this current population such as ancestry and racial mixing may be influencing this finding. No smoking seems to be a protective factor. Awareness of the disclosed risk factor should encourage preventive strategies for LN in SLE patients such as suppression of cigarette smoking.

\section{REFERENCES:}

[1] Pons-estel GJ, Catoggio LJ, Cardiel MH, Bonfa E, Caeiro F, Sato E, et al. Lupus in Latin-American patients: lessons from the GLADEL cohort. 2015;536-45

[2] V. A. Seligman, R. F. Lum JLO. Demographic Differences in the Development of Lupus Nephritis: A Retrospective Analysis. Am J Med. 2002;9343 (2):726-9.
Disclosure of Interest: None declared

DOI: 10.1136/annrheumdis-2018-eular.5619

\section{AB1321 THE EXPANSION OF MYELOID-DERIVED SUPPRESSOR CELLS IN PATIENTS WITH RHEUMATIC DISEASES}

J. Zhu' ${ }^{1}$, S. Chen ${ }^{2}$, L. Wu' ${ }^{2}$ R. Wang ${ }^{2}$, D. Zhao ${ }^{2}$, J. Li'. ${ }^{2}{ }^{1}$ Department of

Rheumatology, Nanfang Hospital Southern Medical University; ${ }^{2}$ Department of Internal Medicine of Traditional Chinese Medicine, College of Traditional Chinese Medicine, Southern Medical University, Guangzhou, China

Background: Myeloid-derived suppressor cells (MDSCs) are a heterogeneous population of immature myeloid cells with a remarkable ability to suppress the immune system. Although MDSCs were found to suppress the T cell response of some cancer patients and tumour bearing mice, the role of those cells have been revealed in patients with RA, SLE, and IBD. Nevertheless, most rheumatic diseases have a common pathological process, such as inflammatory arthritis and systemic tissue damage. Whether or not MDSCs and their subsets are abnormally expressed in patients with inflammatory-associated rheumatic diseases is still unclear.

Objectives: To investigate the proportion of MDSCs and their subsets in patients with different rheumatic diseases and clarify the association between those cells and patients clinical data including the disease activity index and the inflammation of joints.

Methods: One hundred and nine patients with various rheumatic diseases and twenty-five healthy controls were recruited. The common clinical characteristics and the special clinical indexes for each rheumatic disease were obtained from patients. The MDSCs and their subsets were marked with fluorescently labelled antibodies and were then analysed with flow cytometry. All statistics were calculated with SPSS 20.0. A $p<0.05$ was considered to be statistically significant.

Results: The patients included 31 with RA, 21 with AS, 14 with OA, 11 with SLE with arthritis, 13 with SLE without arthritis, 9 with Gout, 10 with HUA, and 25 healthy controls. The proportions of MDSCs, M-MDSCs, and G-MDSCs were higher in patients with RA than in healthy controls $(6.56 \% \pm 6.77 \%$ vs. 1.46 $\pm 0.96 \%, 2.52 \pm 3.81 \%$ vs. $0.35 \pm 0.35 \%, 1.13 \pm 1.64 \%$ vs. $0.18 \pm 0.14 \% ; p<0.001$ ). The same increase in the number of MDSCs and their subsets was also found in patients with AS, OA, SLE with arthritis, and Gout. The proportions of MDSCs and M-MDSCs were mostly correlated with the patient's joint inflammation indexes (such as CRP and total joint pain) and the disease activity. Additionally, an increased risk of arthritis was found from MDSCs, M-MDSCs, and G-MDSCs (OR=2.417, 13.257, 6.204; 95\% Cl=1.625-3.597, 3.974-44.223, 1.798-21.406 $\mathrm{p}<0.01)$. When other cell subsets were adjusted, the same risk was also obtained for the expansion of M-MDSCs (adjusted OR=5.772; 95\% Cl 1.174-28.369; $\mathrm{p}=0.031$ ).

Conclusions: The expansion of MDSCs and their subsets were found to be correlated with the disease activity and joint inflammation in patients with different rheumatic diseases. Further analysis revealed that the proportion of M-MDSCs was associated with the risk of arthritis in those populations.

Acknowledgements: Supported by the Natural Science Foundation of Guang dong Province ${ }^{\text {No. }}{ }^{2017}$ A030313868), and the President Foundation of Nanfang Hospital, Southern Medical University $\left.{ }^{\text {No. }}{ }^{2016} \mathrm{C} 024\right)$. The funders had no role in study design, data collection and analysis, decision to publish, or preparation of the manuscript.

Disclosure of Interest: None declared

DOI: 10.1136/annrheumdis-2018-eular.1136

\section{AB1322 TREATMENT RESPONSE AS A PREDICTOR FOR REFRACTORY DISEASE AND/OR TRANSITION TO RHEUMATOID ARTHRITIS IN PATIENTS WITH POLYMYALGIA RHEUMATICA}

K. Hayashi, K. Ohashi, H. Watanabe, K.-E. Sada, Y. Asano, S. Hiramatsu, Y. Yamamura, Y. Miyawaki, M. Morishita, Y. Matsumoto, T. Kawabata, J. Wada. Department of Nephrology, Rheumatology, Endocrinology and Metabolism, Okayama University Graduate School of Medicine Dentistry and Pharmaceutical Sciences, Okayama, Japan

Background: Polymyalgia rheumatica (PMR) is a common inflammatory rheu matic disease that affects elderly people and predominantly causes shoulder and pelvic girdle pain. PMR is sometimes refractory 1 ), and some cases are finally diagnosed with rheumatoid arthritis (RA) 2). Predictive factors for clinical course of PMR are not fully elucidated.

Objectives: The purpose of this study is to elucidate predictive factors for clinical course of PMR.

Methods: Newly diagnosed PMR patients at our hospital from July 2006 to June 2017 were enrolled. All patients fulfilled the EULAR/ACR 2012 Provisional Classification Criteria for PMR but not the EULAR/ACR 2010 Classification Criteria for RA 